\title{
EDUCAÇÃO DE JOVENS E ADULTOS: CONTRIBUIÇÕES DE ARTIGOS EM PERIÓDICOS BRASILEIROS INDEXADOS NA BASE SCIELO (2010-2014)
}

\author{
Fabiana Marini Braga* \\ Jarina Rodrigues Fernandes **
}

\begin{abstract}
RESUMO: Este trabalho apresenta pesquisa bibliográfica sobre temas, abordagens e proposiçóes de 79 artigos referentes à Educação de Jovens e Adultos (EJA) disponíveis em periódicos brasileiros indexados na base SciELO (2010-2014). Chama a atenção o quantitativo de publicações do quinquênio superar o da década anterior e a concentração de textos voltados à escolarização. Dentre as proposiçóes, está a de uma política de Estado para a EJA, da Alfabetização ao Ensino Médio, considerando os diferentes contextos marcados pela diversidade, e de oferta/aprimoramento de formação docente. Dentre os temas emergentes, destacam-se: Educação Profissional integrada à Educação Básica; Educação na Prisão; e Educação e Saúde. Identificou-se a presença pouco significativa em relação a Arte, Educação Ambiental e História, com silêncio em Tecnologias da Informação e Comunicação e Geografia. A Educação Popular aparece discretamente, contudo, a problematização de questóes teórico-metodológicas remete à reflexão sobre seus princípios na contemporaneidade.
\end{abstract}

Palavras-chave: Educação de jovens e adultos/EJA. Pesquisa em educação.

\footnotetext{
* Universidade Federal de São Carlos, Departamento de Teorias e Práticas Pedagógicas, São Carlos, SP., Brasil. E-mail de contato: fabiana@ufscar.br.

** Universidade Federal de São Carlos, Departamento de Teorias e Práticas Pedagógicas, São Carlos, SP., Brasil. E-mail de contato: jarina.fernandes@ufscar.br.
} 


\title{
Youth and Adult Education: contributions of papers in Brazilian journals indexed in SciELO database (2010-2014)
}

\begin{abstract}
This study presents a bibliographic research on the themes, approaches and propositions of 79 papers related to Youth and Adult Education and available in Brazilian journals indexed in SciELO database (2010-2014). It is possible to note that the quantity of publications in this five-year period exceeds the amount in the previous decade and the concentration of texts focused on schooling also draws attention. Among the propositions, there is a state policy for Youth and Adult Education, the Literacy in High School, considering different contexts marked by diversity and the provision/improvement of teacher education. The following are included among the emergent themes: Professional Education integrated to Basic Education; Education in Prison; Education and Health. There was minimal presence of Arts, Environmental Education and History, and silence in relation to Information and Communication Technologies and Geography. The presence of Popular Education is discreet; however, the problematization of theoretical and methodological issues leads to the reflection on its principles in contemporary times.
\end{abstract}

Keywords: Youth and adult education/EJA. Research in Education.

\section{INTRODUÇÃO}

Educação de Jovens e Adultos (EJA) passa por um contradi-
tório momento no Brasil. Conquistas recentes convivem com
retrocessos, num cenário em que o cumprimento das funçóes reparadora, equalizadora e qualificadora (BRASIL, 2000) tem sido realizado por uma multiplicidade de programas que indicam indefinição das políticas públicas empreendidas. O objetivo do presente trabalho é mapear temas, abordagens e proposiçóes que emergem das publicaçóes de periódicos brasileiros indexados na base Scientific Eletronic Library Online (SciELO), no último quinquênio, a fim de identificar contri- 
buiçóes para o debate, lacunas existentes e, a partir do cenário presente, vislumbrar demandas e perspectivas para o futuro próximo.

Inicialmente, indica-se o caminho metodológico percorrido, seguido por um panorama de quantitativos de artigos do período em comparação à década anterior. Por fim, apresenta-se o mapeamento e a análise realizada, com levantamento de anúncios, desafios e silêncios que os perpassam.

\section{CAMINHO METODOLÓGICO}

Este artigo apresenta pesquisa bibliográfica (SALVADOR, 1986; LIMA; MIOTO, 2007) realizada a partir de revisão de conjunto (SALVADOR, 1986) e análise de conteúdo (BARDIN, 2011)․․ Para identificação dos artigos indexados na base SciELO foram utilizados os seguintes descritores: educação de jovens e adultos, EJA, educação de adultos, educação de pessoas jovens e adultas, juventude e idosos ${ }^{2}$. Adicionou-se aos dois últimos descritores, na busca avançada, os termos EJA, educação de jovens e adultos e educação de adultos, dado o recorte do trabalho. A busca resultou em 242 ocorrências. Excluídas as repetiçóes e uma dissertação de mestrado, foram obtidos 132 diferentes artigos. A leitura flutuante (BARDIN, 2011) dos resumos permitiu identificar 53 artigos que não se enquadravam no escopo do estudo por diferentes razóes: não possuíam relação com a temática da pesquisa, pois a sequência de letras EJA possuía outra significação no texto; focalizava a influência de Freire na educação da infância; tinham foco na formação universitária ou continuada, espaços de aprendizagem profissional compreendidos como formação de adultos ${ }^{3}$; abordavam aspectos relativos à relevância da relação adulto-criança como espaço formativo; apresentavam resultados de pesquisas junto a jovens, adultos e/ou idosos sobre perfis, hábitos, atitudes e outros aspectos relativos à saúde alimentar, atividade física e procedimentos terapêuticos/médicos. Desse modo, após todo o processo obteve-se a lista de 79 artigos para análise. A utilização dos descritores mencionados para captação dos artigos representa um limite, pois possibilita a exclusão de textos que possam ter relação direta com o tema, por não apresentarem no título/resumo/palavras-chave nenhum dos des- 
critores utilizados no presente estudo. Contudo, estabelecer parâmetros para a coleta de dados é ação necessária.

Com base na análise categorial apresentada por Bardin (2011), que envolve a codificação e a categorização, os artigos foram agrupados em cinco categorias: Função reparadora; Trabalho; Educação Popular; Educação ao longo da vida e Sujeitos da EJA. No caso, utilizou-se o procedimento de categorização chamado pela autora de "milha", cujas categorias não são fornecidas a priori, mas sim pela classificação analógica e progressiva dos elementos que permitem defini-las ao final da sistematização.

Para tanto, o balanço da produção aqui apresentado contou com o auxílio de uma ficha de leitura contendo campos de investigação relacionados ao objeto de estudo a serem preenchidos, como por exemplo, o referencial teórico-metodológico abordado, os sujeitos participantes e as temáticas e proposiçóes contempladas em que foi possível identificar a unidade de registro de cada artigo (tema) e sua unidade de contexto (frases ou parágrafos). No caso do presente artigo, fez-se a escolha de organizar quadros por categoria, os quais indicam temas e proposiçóes convergentes das publicaçóes. Após cada quadro, realizou-se uma breve análise das abordagens que perpassam os artigos a fim de anunciar suas contribuiçóes para o debate.

Em torno da categoria Função Reparadora foram reunidos os artigos voltados à superação da privação ocasionada pela falta da Educação Básica, relacionados a contextos de alfabetizaçáo e escolarização de jovens e adultos, exceto aqueles que abordavam a integração da educação profissional à educação básica, os quais foram, por sua especificidade, incluídos numa segunda categoria denominada Trabalho, junto a outras publicaçóes que focalizavam a referida temática. Em torno da categoria Educação ao longo da vida foram reunidos os trabalhos que se referem a diferentes propostas para além da Educação Básica. Já em torno da categoria Sujeitos da EJA foram agrupados os que focalizavam a diversidade dos perfis dos educandos. Por fim, em torno da categoria Educação Popular foram concentrados os trabalhos com contextos de atuação de educadores populares e práticas dos movimentos sociais na EJA. 


\section{PANORAMA REFERENTE À INCIDÊNCIA DE ARTIGOS}

O crescimento contínuo do número de publicaçóes pode ser visualizado na Figura 1, em que se apresentam os quantitativos de artigos obtidos a partir dos descritores que mais contribuíram para a obtenção da lista final de artigos.

\section{Figura 1}

Evolução de artigos na Base SciELO, período 2000-2014

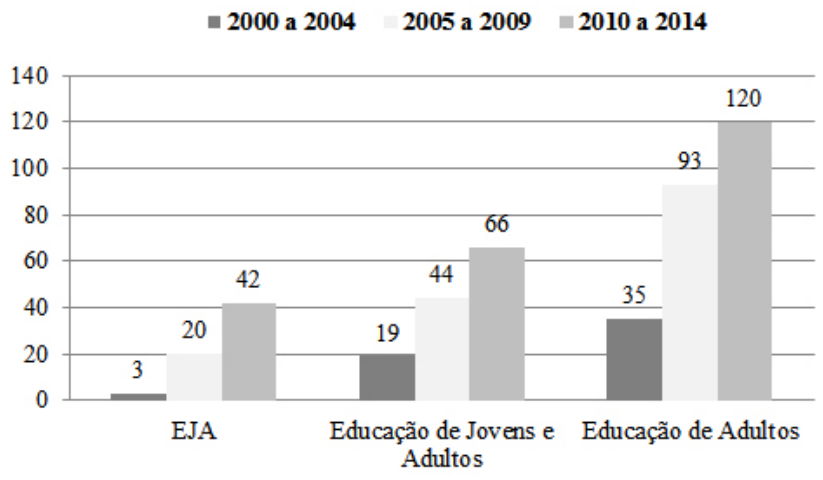

Fonte: Base SciELO

Nos últimos cinco anos foram identificados mais artigos sobre a temática do que na última década, ao considerar os periódicos brasileiros indexados na base SciELO. Nota-se um crescimento expressivo após 2007, situado num quinquênio marcado pela implementação de diversos programas voltados a EJA, como o "Brasil Alfabetizado" e o "Programa Nacional de Integraçáo da Educaçáo Profissional com a Educação Básica na modalidade de Educação de Jovens e Adultos" (Proeja); por movimentos referentes à incorporação da EJA ao Fundo de Manutenção e Desenvolvimento da Educação Básica e de Valorização dos Profissionais da Educação (Fundeb) e preparatórios à VI Conferência Internacional de Educação de Adultos, sediada no Brasil, em sua primeira edição no Hemisfério Sul. (DI PIERRO, 2008; HADDAD, 2009; RODRIGUEZ, 
2009) Em relação ao crescimento, há que se considerar a importância dada às publicaçóes no formato de artigo, contudo, a efervescência de acontecimentos no quinquênio 2005-2009 merece ser destacada.

A seguir, na Tabela 1, encontra-se um panorama com a incidência de publicaçóes nas cinco categorias definidas para a pesquisa, no período de 2010 a 2014.

\section{Tabela 1}

Artigos selecionados por categoria e ano

\begin{tabular}{lcccccc}
\hline \multicolumn{1}{c}{ Categorias } & $\mathbf{2 0 1 0}$ & $\mathbf{2 0 1 1}$ & $\mathbf{2 0 1 2}$ & $\mathbf{2 0 1 3}$ & $\mathbf{2 0 1 4}$ & Total \\
\hline Função reparadora & 5 & 6 & 4 & 13 & 12 & 40 \\
Trabalho & 3 & 3 & 3 & 3 & 2 & 14 \\
Sujeitos da EJA & 2 & 2 & 0 & 3 & 4 & 11 \\
Educação ao longo da vida & 1 & 3 & 1 & 2 & 2 & 9 \\
Educação popular & 1 & 2 & 1 & 0 & 1 & 5 \\
\hline Total & & & & & & $\mathbf{7 9}$ \\
\hline
\end{tabular}

Fonte: Tabulaçẫo das autoras.

A Tabela 1 revela que 50,7\% das publicaçóes se referem a questôes relacionadas à função reparadora da EJA, num período que continuou a ser marcado por decréscimos anuais consecutivos de matrículas no segmento. Destaca-se a presença de trabalhos relacionados a duas categorias sem forte expressão na década anterior: Trabalho e Sujeitos da $E J A$, respectivamente, responsáveis por $17,7 \%$ e $13,9 \%$ dos trabalhos. Aqueles voltados à Educação ao longo da vida correspondem a 11,4\% dos artigos selecionados. É importante destacar, também, que apenas 6,3\% das publicaçôes emergem da categoria Educação popular.

\section{MAPEAMENTO DE TEMAS, ABORDAGENS E PROPOSIÇÕES}

Os 40 artigos referentes à categoria Função Reparadora foram organizados em torno de quatro temas: Políticas $(A 1-A 10)^{4}$; Práticas pedagógicas/escolares (A11-A30); Currículo (A31-A33) e Formação inicial/continuada (A34-A40), conforme a Tabela 2. 


\section{Tabela 2}

Temas e Proposições de artigos da categoria Função reparadora

\begin{tabular}{|c|c|c|c|c|}
\hline Temas & Cód. & Autor(es) & Ano & Proposições \\
\hline \multirow{3}{*}{ Políticas } & $\begin{array}{l}\mathrm{A} 1 \\
\mathrm{~A} 2 \\
\mathrm{~A} 3\end{array}$ & $\begin{array}{c}\text { Di Pierro } \\
\text { Araújo } \\
\text { Volpe }\end{array}$ & $\begin{array}{l}2010 \\
2012 \\
2013 \\
\end{array}$ & $\begin{array}{c}\text { Revisão/ampliação de financiamento } \\
\text { (Fundeb) }\end{array}$ \\
\hline & $\begin{array}{l}\text { A4 } \\
\text { A5 } \\
\text { A6 } \\
\text { A7 } \\
\text { A8 } \\
\text { A9 }\end{array}$ & $\begin{array}{c}\text { Barreyro } \\
\text { Friedrich et.al } \\
\text { Catelli; Gisi; Serrao } \\
\text { Andriola } \\
\text { Barcelos } \\
\text { Stromquist } \\
\end{array}$ & \begin{tabular}{l|}
2010 \\
2012 \\
2013 \\
2014 \\
2014 \\
2012 \\
\end{tabular} & $\begin{array}{l}\text { Necessidade de rever e garantir } \\
\text { padrões minimos de qualidade nos } \\
\text { programas e propostas educacionais }\end{array}$ \\
\hline & $\mathrm{A} 10$ & Silva; Bonamino; Ribeiro & 2012 & $\begin{array}{c}\text { PEJA (equipe integrada no processo } \\
\text { de ensino) }\end{array}$ \\
\hline \multirow{10}{*}{$\begin{array}{c}\text { Práticas } \\
\text { pedagógico } \\
\text { escolares }\end{array}$} & $\begin{array}{l}\mathrm{A} 11 \\
\mathrm{~A} 12 \\
\end{array}$ & $\begin{array}{l}\text { Bottino; Emmerick; Soares } \\
\text { Lima; Selva }\end{array}$ & $\begin{array}{l}2010 \\
2013 \\
\end{array}$ & Estratégias de intervenção docente \\
\hline & A13 & Laffin; Nakayama & 2013 & Compreensão da mediação docente \\
\hline & $\begin{array}{l}\mathrm{A} 14 \\
\mathrm{~A} 15\end{array}$ & $\begin{array}{l}\text { Vargas; Gomes } \\
\text { Moreira; Ferreira }\end{array}$ & $\begin{array}{l}2013 \\
2011\end{array}$ & $\begin{array}{l}\text { Relação entre conhecimento } \\
\text { cientifico e realidade }\end{array}$ \\
\hline & $\begin{array}{l}\text { A16 } \\
\text { A17 } \\
\text { A18 } \\
\text { A19 } \\
\text { A20 } \\
\end{array}$ & $\begin{array}{c}\text { Ferreira } \\
\text { Fonseca; Simões } \\
\text { Pavanello; Lopes; Araujo } \\
\text { Pedralli; Ceruti, Rizzatti } \\
\text { Baltar; Costa } \\
\end{array}$ & \begin{tabular}{l|}
2013 \\
2014 \\
2011 \\
2013 \\
2010 \\
\end{tabular} & Práticas reflexivas e dialogadas \\
\hline & \begin{tabular}{l|}
$\mathrm{A} 21$ \\
$\mathrm{~A} 22$ \\
$\mathrm{~A} 23$ \\
$\mathrm{~A} 24$
\end{tabular} & $\begin{array}{c}\text { Zimmermann } \\
\text { Nobre; Roazzi } \\
\text { Campos; Tenani; Berti } \\
\text { Gomes } \\
\end{array}$ & $\begin{array}{l}2014 \\
2011 \\
2012 \\
2011 \\
\end{array}$ & $\begin{array}{l}\text { Mediação entre cultura, } \\
\text { conhecimento e linguagem }\end{array}$ \\
\hline & $\begin{array}{l}\mathrm{A} 25 \\
\mathrm{~A} 26 \\
\end{array}$ & $\begin{array}{l}\text { Borges; Aranha; Sabino } \\
\text { Pedroso; Andrade }\end{array}$ & \begin{tabular}{l|}
2010 \\
2014 \\
\end{tabular} & Práticas atrativas e contextualizadas \\
\hline & A27 & Schneider; Fonseca & 2013 & $\begin{array}{c}\text { Práticas laborais em } \\
\text { matemática/relações intergeracionais }\end{array}$ \\
\hline & A28 & Vovio; Kleiman & 2013 & $\begin{array}{l}\text { Revisão iniciativas sobre } \\
\text { letramento/alfabetização }\end{array}$ \\
\hline & A29 & Brito; Campos; Romanatto & 2014 & Prática inclusiva em matemática \\
\hline & $\mathrm{A} 30$ & Abrantes & 2014 & Trabalho a partir de autobiografias \\
\hline \multirow{2}{*}{ Currículo } & A31 & Carvalho & 2012 & $\begin{array}{c}\text { Compreensão de currículo } \\
\text { Intercultural } \\
\end{array}$ \\
\hline & $\begin{array}{l}\mathrm{A} 32 \\
\mathrm{~A} 33\end{array}$ & $\begin{array}{c}\text { Adelino; Fonseca } \\
\text { Januario; Freitas; Lima }\end{array}$ & $\begin{array}{l}2014 \\
2014 \\
\end{array}$ & Materiais didáticos contextualizados \\
\hline \multirow{6}{*}{$\begin{array}{l}\text { Formação } \\
\text { inicial/ } \\
\text { continuada }\end{array}$} & A34 & Marques; Pachane & 2010 & $\begin{array}{l}\text { Melhoria formação docente } \\
\text { EJA/idosos }\end{array}$ \\
\hline & A 35 & Soares & 2011 & $\begin{array}{l}\text { Influência das relações dialógicas } \\
\text { Freire }\end{array}$ \\
\hline & A36 & Fonseca-Janes; Omote & 2013 & Educação inclusiva \\
\hline & $\begin{array}{l}\text { A37 } \\
\text { A38 } \\
\end{array}$ & $\begin{array}{c}\text { Andriola } \\
\text { Onofre; Julião }\end{array}$ & \begin{tabular}{l|}
2013 \\
2013 \\
\end{tabular} & Educação nas prisões \\
\hline & A39 & Silva; Silva Neto & 2013 & $\begin{array}{l}\text { Introdução do conceito de Lingua na } \\
\text { formação inicial }\end{array}$ \\
\hline & A40 & Rodrigues & 2014 & $\begin{array}{l}\text { Redefinição do papel do psicólogo } \\
\text { na escola }\end{array}$ \\
\hline
\end{tabular}

Fonte: Tabulação das autoras. 
Observa-se que 10 dos 40 artigos, de $A 1$ a $A 10$, encontram-se voltados à análise de políticas. Di Pierro (2010), Araújo (2012) e Volpe (2013) enfatizam a necessidade de revisão do Fundeb em relação à EJA. Já Barreyro (2010), Friedrich et al (2012), Catelli; Gisi; Serrao (2013), Andriola (2014), Barcelos (2014), Stromquist (2012) e Silva; Bonamino; Ribeiro (2012) apontam a necessária reavaliação em práticas pautadas na concepção de EJA como educação compensatória. A ênfase dada às práticas de alfabetização/letramento (FERREIRA, 2013; PEDRALLI; CERUTI, RIZZATTI, 2013; CAMPOS; TENANI; BERTIM 2012; VOVIO; KLEIMAN, 2013), leitura e escrita (BOTTINO; EMMERICK; SOARES, 2010; VARGAS; GOMES, 2013; PAVANELLO; LOPES; ARAUJO, 2011; ZIMMERMANN, 2014; NOBRE; ROAZZI, 2011; GOMES, 2011; ABRANTES, 2014) e matemática (LIMA; SELVA, 2013; FONSECA; SIMÓES, 2014; PAVANELLO; LOPES; ARAUJO, 2011; SCHNEIDER; FONSECA, 2013; BRITO; CAMPOS; ROMANATTO, 2014; ADELINO; FONSECA, 2014; JANUARIO; FREITAS; LIMA, 2014) é marcante na produção do quinquênio, incluindo o Ensino Médio. São poucas as pesquisas que abordam outras áreas, como por exemplo, a de Moreira; Ferreira (2011) apresenta uma proposta de seminários interativos no ensino de Ciências e Biologia; a de Baltar; Costa (2010) pela exposição de sequência didática radiofônica para trabalho com gênero oral; a de Borges; Aranha; Sabino (2010) pela utilização da fotografia como instrumento para trabalhar a Educação Ambiental e a de Pedroso; Andrade (2014) por englobar a articulaçấo da disciplina de História com a realidade dos alunos.

Verifica-se que 26 artigos são pesquisas empíricas, sendo que, dessas, apenas três são relatos de experiência. Chamam a atenção as pesquisas que traçam comparaçóes entre adultos e crianças (NOBRE; ROAZZI, 2011; CAMPOS; TENANI; BERTI, 2013) sobre o processo de suas aprendizagens. Chamam a atenção as pesquisas de Nobre e Roazzi (2011) e Tenani e Berti (2013) que traçam comparaçóes entre adultos e crianças sobre o processo de suas aprendizagens e concluem que os adultos superam mais rapidamente alguns conceitos e aprendizagens do que as crianças, pelo fato de suas inserçóes sociais. Zimmermann (2014) afirma, com base em um estudo comparativo entre adultos com diferentes anos de escolaridade, que a idade teve menor influência em seus desempenhos escolares. As relaçôes intergeracionais e o currículo 
intercultural são discussões traçadas por Schneider; Fonseca (2013) e Carvalho (2012) em busca de relaçóes mais respeitosas na EJA.

As pesquisas de $A 11$ a $A 34$ convergem em práticas e concepçóes que valorizam os educandos como "sujeitos de conhecimento" (FREIRE, 2008) e apostam no papel do docente mediador. A educação especial é abordada por Brito; Campos; Romanatto (2014), tendo em vista a eficácia dos jogos para o trabalho com Matemática. Por fim, as pesquisas sobre formação indicam algumas necessidades de revisão de currículos na formação inicial (FONSECA-JANES; OMOTE, 2013; SILVA; SILVA NETO, 2013), atuação escolar (RODRIGUES, 2014) e melhor formação docente em relação à EJA e, mais especificamente, em relação ao idoso (MARQUES; PACHANE, 2010). A formação inicial e continuada, voltada à educação nas prisóes, é foco em Andriola (2013) e Onofre; Julião (2013).

\section{Tabela 3}

Temas e Proposições de artigos da categoria Trabalho

\begin{tabular}{|c|c|c|c|c|}
\hline Temas & Cód. & Autor(es) & Ano & Proposições \\
\hline \multirow{3}{*}{ Políticas } & A41 & Rummert; Alves & 2010 & \multirow{3}{*}{ Politicas de Estado } \\
\hline & $\mathrm{A} 42$ & Moraes & 2013 & \\
\hline & A43 & Moraes; Alavarse & 2013 & \\
\hline \multirow{6}{*}{ Currículo } & A44 & Ciavatta; Rummert & 2010 & \multirow{2}{*}{$\begin{array}{l}\text { Compreensão de concepções } \\
\text { do currículo integrado }\end{array}$} \\
\hline & A45 & $\begin{array}{l}\text { Friedrich; Benite, C; } \\
\text { Benite, A. }\end{array}$ & 2012 & \\
\hline & A46 & \multirow{2}{*}{ Miranda; Gazire } & 2012 & \multirow{2}{*}{$\begin{array}{c}\text { Materiais didáticos } \\
\text { contextualizados }\end{array}$} \\
\hline & $\mathrm{A} 47$ & & 2013 & \\
\hline & A48 & Costa; Echeverria & 2013 & Problematização das relações \\
\hline & A49 & & 2014 & $\begin{array}{l}\text { entre escola, conhecimento, } \\
\text { cultura e currículo }\end{array}$ \\
\hline \multirow{4}{*}{$\begin{array}{c}\text { Trabalho } \\
\text { docente }\end{array}$} & A50 & Ivo; Hipólito & 2013 & \multirow{4}{*}{$\begin{array}{l}\text { Revisão de condições e } \\
\text { precarização; açoses mais } \\
\text { próximas aos professores }\end{array}$} \\
\hline & A51 & Shiroma; Lima Filho & 2011 & \\
\hline & A52 & Silva & 2011 & \\
\hline & A53 & Guimarães & 2010 & \\
\hline Inclusão & A54 & Riaño-Galán et al. & 2014 & $\begin{array}{l}\text { Aprimoramento de programas } \\
\text { para pessoas com deficiências }\end{array}$ \\
\hline
\end{tabular}

Fonte: Tabulação das autoras. 
Os 14 artigos referentes à categoria Trabalho foram agrupados em quatro temas: Políticas (A41-A43); Currículo (A44-A47); Trabalho docente (A48-A53) e Inclusão $(A 54)$, conforme demonstrado na Tabela 3 . Verifica-se que 12 artigos, de $A 41$ a $A 52$, tratam da realidade brasileira, sendo que Rummert e Alves (2010) traçam um paralelo com a realidade portuguesa. A retomada da concepção ontológica do trabalho, tendo em vista a integração da educação profissional e educação básica na modalidade EJA, é uma significativa contribuição desse quinquênio. Ao recuperar histórico das políticas (RUMMERT; ALVES, 2010; MORAES, 2013), resgata-se o papel da educação popular nesse processo (MORAES, 2013) e a premência de substituição de programas por políticas de Estado emancipatórias. Há artigos que convidam a refletir sobre implicaçóes, conquistas e desafios para a construção de um currículo integrado (CIAVATTA; RUMMERT, 2010; FRIEDRICH; BENITE, C.; BENITE, A., 2012; MIRANDA; GAZIRE, 2012, 2013; COSTA; ECHEVERRIA, 2013), o que passa pela adesão dos professores. Shiroma e Lima Filho (2011), Silva (2011) e Ivo e Hipólito (2013) ressaltam ser necessário observar a falta de condiçôes para o trabalho docente e empreender açóes mais próximas aos professores tanto no Brasil, o que também é destacado por Guimarães (2010) no contexto de Portugal. O diálogo a partir das práticas laborais dos educandos provoca a problematizaçáo do papel dos seus conhecimentos na escola, a partir de diferentes perspectivas teóricas (COSTA; ECHEVERRIA, 2013; SCHNEIDER; FONSECA, 2014). Por fim, o trabalho de Riaño-Galán et al (2014) difere dos demais ao investigar expectativas diante de centros educativos europeus voltados à inclusão de pessoas com deficiência e ao seu ajustamento ao trabalho.

Os nove artigos da categoria Educação ao longo da vida foram organizados em torno de quatro temas: Saúde (A55-A59); Arte (A60); (Re)Inserção social (A61-A62) e Leitura (A63), conforme a Tabela 4. Verifica-se que cinco dos nove artigos apresentam resultados de pesquisas empíricas junto a participantes de iniciativas voltadas à saúde, com diferentes focos: educação alimentar na obesidade (BUENO et al, 2011) e para adolescentes e adultos (SILVA et al, 2014), atividade física para pessoas com deficiência (LEHNHARD; MANTA; PALMA, 2012) e saúde alternativa para pais e filhos em Medellín (PEÑARANDA-CORREA et al, 2011). As pesquisas convergem ao buscar conhecer sentidos e 
práticas dos sujeitos envolvidos, tendo em vista o sucesso das propostas. Peñaranda-Correa et al (2011) e Draganov; Friedländer; Sanna (2011) convidam ao debate teórico-metodológico, no qual a concepção de práxis e as contribuiçóes da Andragogia apontam para diferentes direçóes. $\mathrm{Na}$ perspectiva da Arte, Almeida, Azevedo-Martins e Nunes (2013) afirmam a relevância do fazer artístico na maturidade e para todas as idades, com resistência ao trabalho com o corpo e teatro reduzido ao cultivo da saúde dos idosos. Julião (2010) e Chrispino e Gonçalves (2013), ao tratarem, respectivamente, de problematizaçôes relativas à educação na prisão e ao propor o trabalho com visão de futuro e resiliência diante da violência escolar, dão uma mostra de diferentes abordagens para questóes atravessadas pelas injustiças sociais. Por fim, Martins (2014) focaliza bibliotecas atrativas para jovens e adultos trabalhadores, com destaque ao papel mediador do bibliotecário.

\section{Tabela 4}

Temas e Proposiçóes de artigos da categoria Educação ao longo da vida

\begin{tabular}{|c|c|c|c|c|}
\hline Temas & Cód. & Autor(es) & Ano & Proposições \\
\hline \multirow{3}{*}{ Saúde } & $\begin{array}{l}\text { A55 } \\
\text { A56 } \\
\text { A57 }\end{array}$ & $\begin{array}{c}\text { Bueno et al } \\
\text { Silva et al } \\
\text { Lehnhard; Manta; } \\
\text { Palma }\end{array}$ & $\begin{array}{l}2011 \\
2014 \\
2012\end{array}$ & $\begin{array}{c}\text { Criação e aprimoramento de } \\
\text { programas voltados à vida } \\
\text { saudável }\end{array}$ \\
\hline & A58 & $\begin{array}{c}\text { Peñaranda-Correa et } \\
\text { al. }\end{array}$ & 2011 & Educação problematizadora \\
\hline & A59 & \begin{tabular}{|c|} 
Draganov; \\
Friedländer; Sanna \\
\end{tabular} & 2011 & $\begin{array}{c}\text { Contribuições da } \\
\text { Andragogia }\end{array}$ \\
\hline Arte & A60 & $\begin{array}{c}\text { Almeida, Azevedo- } \\
\text { Martins; Nunes }\end{array}$ & 2013 & $\begin{array}{c}\text { Espaços para explorar o } \\
\text { corpo, a sensibilidade, o } \\
\text { teatro na maturidade e em } \\
\text { todas as idades }\end{array}$ \\
\hline \multirow{2}{*}{$\begin{array}{c}\text { (Re)Inserção } \\
\text { social }\end{array}$} & A61 & Julião & 2010 & $\begin{array}{l}\text { Politicas efetivas para } \\
\text { reinserção social de }\end{array}$ \\
\hline & A62 & $\begin{array}{l}\text { Chrispino; } \\
\text { Gonçalves }\end{array}$ & 2013 & $\begin{array}{l}\text { Redução da violência nas } \\
\text { escolas }\end{array}$ \\
\hline Leitura & A63 & Martins & 2014 & $\begin{array}{c}\text { Bibliotecas atrativas aos } \\
\text { trabalhadores }\end{array}$ \\
\hline
\end{tabular}

Fonte: Tabulação das autoras. 
Os 11 artigos da categoria Sujeitos foram organizados em cinco temas: Gênero (A64-A67); Adolescência (A68); Juventude (A69-A70); Alunos com necessidades especiais $(A 71-A 72)$ e Velhice $(A 73-A 74)$, conforme a Tabela 5.

\section{Tabela 5}

Temas e Proposiçóes de artigos da categoria Sujeitos

\begin{tabular}{|c|c|c|c|c|}
\hline Temas & Cód. & Autor(es) & Ano & Proposições \\
\hline \multirow{3}{*}{ Gênero } & A64 & Ribas & 2014 & $\begin{array}{c}\text { Música enquanto prática social } \\
\text { na vida das mulheres }\end{array}$ \\
\hline & $\begin{array}{l}\text { A65 } \\
\text { A66 }\end{array}$ & Souza; Fonseca & $\begin{array}{l}2013 a \\
2013 b\end{array}$ & $\begin{array}{l}\text { Discussão das práticas que } \\
\text { naturalizam as diferenças }\end{array}$ \\
\hline & A67 & Madureira & 2014 & $\begin{array}{l}\text { Articulação entre diferentes } \\
\text { setores para prevenção da } \\
\text { violência contra a mulher }\end{array}$ \\
\hline Adolescência & A68 & Macedo & 2013 & $\begin{array}{l}\text { Espaços para discussão sobre } \\
\text { sexualidade }\end{array}$ \\
\hline Juventude & $\begin{array}{l}\text { A69 } \\
\text { A70 }\end{array}$ & $\begin{array}{l}\text { Andrade; Meyer } \\
\text { Barros }\end{array}$ & $\begin{array}{l}2014 \\
2010\end{array}$ & $\begin{array}{l}\text { Escolaridade como eixo de } \\
\text { mobilização social }\end{array}$ \\
\hline \multirow{2}{*}{$\begin{array}{c}\text { Alunos com } \\
\text { necessidades } \\
\text { especiais }\end{array}$} & A71 & Castro; Almeida & 2014 & $\begin{array}{c}\text { Aprimoramento das condições } \\
\text { de acessibilidade }\end{array}$ \\
\hline & A72 & Resende; Lacerda & 2013 & $\begin{array}{c}\text { Ações junto a alunos surdos na } \\
\text { EJA }\end{array}$ \\
\hline \multirow{2}{*}{ Idosos } & A73 & Peres & 2011 & $\begin{array}{l}\text { Compreensão de exclusão social } \\
\text { articulada com gênero, classe, } \\
\text { etnia/raça e lugar de origem }\end{array}$ \\
\hline & A74 & Ordonez; Cachioni & 2011 & $\begin{array}{c}\text { Oferta de atividades que } \\
\text { promovam criatividade, } \\
\text { participação e qualidade de vida }\end{array}$ \\
\hline
\end{tabular}

Fonte: Tabulação das autoras.

Nota-se que oito dos 11 artigos apresentam resultados de pesquisas empíricas, sendo que, desses, há apenas um relato de experiência. De diferentes formas, Souza; Fonseca (2013a e 2013b) enfatizam a necessidade de abordar as desigualdades de gênero a partir do trabalho com os conteúdos escolares. Madureira (2014) dedica-se ao estudo do perfil dos homens autores de violência contra as mulheres, afirmando a 
necessária articulação de ações de enfrentamento desta entre diferentes setores, como a educação, segurança, saúde, assistência social etc. Macedo (2013) destaca a importância de a sexualidade ser discutida em sala de aula com as/os adolescentes na EJA. Na perspectiva da inclusão, Castro; Almeida (2014) e Resende; Lacerda (2013) ressaltam o desafio ainda presente para um melhor planejamento das ações de diferentes segmentos. Andrade; Meyer (2014), Barros (2010) e Peres (2011) destacam a influência do gênero, raça/etnia, classe social e contexto de origem nas trajetórias escolares de jovens adultos e pessoas idosas. Por fim, Ordinez; Cachioni (2011) apontam contribuiçôes para o desenvolvimento de propostas educativas, criativas e participativas junto a pessoas idosas.

Os cinco artigos da categoria Educação Popular foram agrupados em torno de três temas: Transformação nos sujeitos (A75); EJA do/no campo (A7G) e Educação pública popular (A78-A79), como na Tabela 6 .

\section{Tabela 6}

Temas e Proposições de artigos da categoria Educação Popular

\begin{tabular}{c|c|c|c|c}
\hline Temas & Cód. & Autor(es) & Ano & Proposições \\
\hline $\begin{array}{c}\text { Transformação } \\
\text { nos sujeitos }\end{array}$ & A75 & Campos; Pachane & 2010 & $\begin{array}{c}\text { Compreensão de } \\
\text { transformações nos sujeitos a } \\
\text { partir da educação popular }\end{array}$ \\
\hline EJA do/no campo & A76 & Silva; Costa; Rosa & 2011 & Avanço na construção da EJA \\
& A78 & Azevedo & 2011 & Souza \\
\hline $\begin{array}{c}\text { Educação pública } \\
\text { popular }\end{array}$ & A79 & Franco & 2012 & $\begin{array}{c}\text { EJA como eixo para a } \\
\text { implementação da escola } \\
\text { democrática }\end{array}$ \\
\hline
\end{tabular}

Fonte: Tabulação das autoras.

Campos e Pachane (2010) apontam percepçóes de transformaçóes em todos os sujeitos envolvidos, formadores, educadoras populares e educandos, a partir de análise de narrativas das educadoras que revelam atitude autoral e abertura à ressignificação da vida, consoantes às concepçôes da Educação Popular. Silva; Costa; Rosa (2011) e Azevedo (2011) indicam a premência da construção de uma EJA do (e não no) campo, 
o que é corroborado pela pesquisa apresentada em Souza (2012) que, ao se debruçar sobre registros de educadores do Movimento de Educação de Base no início dos anos 1960, convida a refletir sobre a adesão e a resistência dos camponeses a princípios/projetos externos à sua cultura, questôes que se repetem na contemporaneidade no campo e em outros contextos. Franco (2014) volta-se para a gestão de Paulo Freire na Secretaria Municipal de São Paulo (1989-1991), com destaque a importância dada à EJA na construção da escola democrática.

\section{ACERCA DOS RESULTADOS: À GUISA DE CONSIDERAÇÕES FINAIS}

O volume de artigos mapeados demanda uma análise pormenorizada que será desenvolvida em publicaçóes futuras. Nesse tópico final, encontram-se destaques relativos aos anúncios, desafios e silêncios identificados em cada categoria.

A maioria dos artigos revela preocupaçóes relativas à escolarização, pois além daqueles artigos voltados à Função Reparadora quase a totalidade dos artigos da categoria Trabalho, além de outros das categorias Sujeitos e Educação popular remetem à questão.

Dentre as proposições da categoria Função Reparadora, destaca-se a necessidade de: revisão da destinação de recursos para a EJA via Fundeb; currículos capazes de relacionar os conteúdos entre si e com os saberes dos educandos; política pública para a formação docente inicial e continuada. Em relação a conteúdos, destaca-se a concentração de artigos relativos à Alfabetização/Letramento/Leitura/Escrita e à Matemática, sem forte expressão de outras áreas. O silêncio sobre Arte, Geografia, Educação Física e Tecnologias no currículo escolar também se destaca. Chama a atenção positivamente o aparecimento de artigos sobre práticas reflexivas e dialógicas que denotam a compreensão do aluno enquanto sujeito de cultura, de linguagem, de saberes. Os trabalhos sobre a prática inclusiva e acerca da violência contra a mulher também são vistos como importantes anúncios. 
A significativa incidência de artigos que abordam Trabalho na EJA é uma marca do quinquênio. A retomada da concepção ontológica do trabalho, tendo em vista a integração da educação profissional e da educaçáo básica na modalidade EJA, sobretudo, por meio do Proeja, agrega à EJA discussôes e práticas significativas. Há que se considerar os resultados das pesquisas realizadas, tendo em vista o desenvolvimento de políticas de Estado emancipatórias. Não se pode ignorar também a magnitude de recursos investidos no Programa Nacional de Acesso ao Ensino Técnico e Emprego - em direção oposta às Diretrizes Curriculares Nacionais do Ensino Médio (BRASIL, 2011) e Diretrizes Curriculares Nacionais para a Educação Profissional Técnica de Nível Médio (BRASIL, 2012) -, o qual necessita ser avaliado e pesquisado.

Outra marca do período é a preocupação em pesquisar os perfis dos educandos. Pesquisas relativas a diversidades de gênero, geracionais, étnico-raciais, de classe social, ocasionadas por deficiências são uma mostra do leque de contribuições que existem e poderão se multiplicar nos anos vindouros. Em relação à categoria Educação ao longo da vida, destaca-se a preocupação com o cultivo da vida saudável, a fim de superar riscos de doenças crônicas. Vale ressaltar que 33 artigos excluídos se referiam a pesquisas sobre Saúde, junto a jovens, adultos e idosos que, se não versavam sobre iniciativas educacionais, apontavam a necessidade de investimentos nesse campo. A defesa da Arte dentre as propostas de Educação ao longo da vida aparece timidamente. Educação Ambiental só aparece num artigo referente ao contexto escolar, enquanto no quinquênio anterior fora produzido um balanço da produção na área de educação não escolar de adultos e educação ambiental (FISCHER, 2009). Artigos voltados à urgência de políticas voltadas para a reinserção social de sujeitos em privação de liberdade e para sujeitos envolvidos em situaçóes de violência escolar indicam ser premente ouvir os sujeitos para a definição de políticas efetivas.

Destaca-se também a pouca incidência de publicações de artigos da categoria Educação popular. Concorda-se com Moraes (2013) que a trajetória de políticas de caráter emancipatório para a educação de jovens e adultos trabalhadores encontra-se fortemente influenciada por movimentos de educação popular e o número discreto de publicaçôes nessa categoria é sinal que deve ser observado. Contudo, há que 
se ressaltar, também, o fato de que os artigos permeados por questóes teórico-metodológicas, presentes nas outras categorias, remetem à necessária reflexão sobre as implicações dos princípios da Educação Popular na contemporaneidade.

Diante do avanço quantitativo das publicaçóes sobre a temática na base SciELO, no período definido para a pesquisa (2010-2014), faz-se necessário aprofundar a compreensão dos achados das pesquisas e lacunas existentes, com o intuito de promover avanços em relação às diversas dimensóes que compóem o campo da EJA.

\section{REFERÊNCIAS}

BARDIN, L. A análise de conteúdo. São Paulo: Edições 70, 2011.

BRASIL. Resolução CNE/CEB no 1 , de 05 de julho de 2000. Estabelece as Diretrizes Curriculares Nacionais para a Educação e Jovens e Adultos. Câmara de Educação Básica do Conselho Nacional de Educação, 2000. Disponível em: $<$ http://portal.mec.gov.br>. Acesso em: 16 jan. 2015.

. Parecer CNE/CEB no 5, de 04 de maio de 2011. Institui as Diretrizes Curriculares Nacionais para o Ensino Médio. Câmara de Educação Básica do Conselho Nacional de Educação, 2011. Disponível em: <http://portal.mec.gov. br>. Acesso em: 16 jan. 2015.

. Resolução CNE/CEB nº6, de 20 de setembro de 2012. Define Diretrizes Curriculares Nacionais para a Educação Profissional Técnica de Nível Médio. Câmara de Educação Básica do Conselho Nacional de Educação, 2012. Disponível em: <http://portal.mec.gov.br>. Acesso em: 16 jan. 2015.

DI PIERRO, M. C. Educação de Jovens e Adultos na América Latina e Caribe: Trajetória Recente. Cad. Pesq., v. 38, n.134, maio/ago., 2008.

FISCHER, N. B. Educação não-escolar de adultos e educação ambiental: um balanço da produção de conhecimentos. Rev. Bras. Educ., Rio de Janeiro, v. 14, n. 41, maio/ago., 2009.

FREIRE, P. Pedagogia do Oprimido. Rio de Janeiro: Paz e Terra, 2008.

HADDAD, S. A participação da sociedade civil brasileira na educação de jovens e adultos e na CONFINTEA VI. Rev. Bras. Educ., v. 14, n. 41, maio/ago., 2009. 
LIMA, T. C. S; MIOTO, R. C. T. Procedimentos metodológicos na construção do conhecimento científico: a pesquisa bibliográfica. Revista Katálisis, Florianópolis, v. 10. p. 37-45, 2007.

MORAES, C. S. V. Educação de jovens e adultos trabalhadores de qualidade: regime de colaboração e Sistema Nacional de Educação. Educ. Soc., Campinas, v. 34, n. 124, jul./set., 2013.

RODRIGUEZ, L. M. Educação de jovens e adultos na América Latina: políticas de melhoria ou de transformação: reflexóes com vistas à VI CONFINTEA. Rev. Bras. Educ., v. 14, n. 41, p. 326-334, 2009.

SALVADOR, A. D. Métodos e técnicas de pesquisa bibliográfica. 3. ed., Porto Alegre: Sulina, 1986.

\section{ANEXO}

\section{ARTIGOS ACESSADOS NA BASE SCIELO ATÉ 12 FEV. 2015}

ABRANTES, P. De como escrevemos a vida e a vida se inscreve em nós: um estudo da socialização através da análise de autobiografias. Educ. Soc., Campinas, v. 35, n. 126, jan./mar. 2014.

ADELINO, P. R.; FONSECA, M. C. F. R. Matemática e texto: práticas de numeramento num livro didático da educação de pessoas jovens e adultas. Rev. Bras. Educ., Rio de Janeiro, v. 19, n. 56, mar. 2014.

ALMEIDA, E. B.; AZEVEDO-MARTINS, A. K.; NUNES; V. A. O corpo como espaço de aprendizagem: reflexóes a partir das vivências de um grupo de teatro formado por adultos na maturidade. Pro-Posiçóes, Campinas, v. 24, n. 3, dez. 2013.

ANDRADE, S. S.; MEYER, D. E. Juventudes, moratória social e gênero: flutuações identitárias e $(\mathrm{m})$ histórias narradas. Educ. Rev., Curitiba, Edição especial, 2014.

ANDRIOLA, W. B. Avaliação diagnóstica da Educação de Jovens e Adultos (EJA) no Brasil. Ensaio: aval. pol. públ. educ., Rio de Janeiro, v. 22, n. 82, mar. 2014.

- Açôes de formação em EJA nas prisóes: o que pensam os professores do sistema prisional do Ceará? Educ. Real., Porto Alegre, v. 38, n. 1, mar. 2013. 
ARAUJO, R. L. S. Desvendando o perfil dos gastos educacionais dos municípios brasileiros. Educ. Soc., Campinas, v. 33, n. 121, dez. 2012.

AZEVEDO, A. A. Trabalhar com os braços e a cabeça para ver o futuro...: representaçôes sobre educaçáo a partir de trabalhadores rurais assentados da reforma agrária. Educ. Rev., Curitiba, n. 40, jun. 2011.

BALTAR, M. A. R.; COSTA, D. R. Gênero textual exposição oral na educação de jovens e adultos. Rev. bras. ling. apl., Belo Horizonte, v. 10, n. 2, 2010.

BARCELOS, L. B. O que é qualidade na educação de jovens e adultos? Educ. Real., Porto Alegre, v. 39, n. 2, jun. 2014.

BARREYRO, G. B. O "Programa Alfabetização Solidária": terceirização no contexto da reforma do Estado. Educ. Rev., Curitiba, n. 38, dez. 2010.

BARROS, M. M. L. Trajetórias de jovens adultos: ciclo de vida e mobilidade social. Horiz. Antropol., Porto Alegre, v. 16, n. 34, dez. 2010.

BORGES, M. D.; ARANHA, J. M.; SABINO, J. A. Fotografia de natureza como instrumento para educação ambiental. Ciênc. Educ., Bauru, v. 16, n. 1, 2010 .

BOTTINO, A. G.; EMMERICK, T. A.; SOARES, A. B. Promovendo a compreensão de textos em estudantes alfabetizados na infância e na idade adulta. Educ. Rev., Curitiba, n. 38, dez. 2010.

BRITO, J.; CAMPOS, J. A. P. P.; ROMANATTO, M. C. Ensino da matemática a alunos com deficiência intelectual na educação de jovens e adultos. Rev. bras. educ. espec., Marília, v. 20, n. 4, dez. 2014.

BUENO, J. M. et al. Educação alimentar na obesidade: adesão e resultados antropométricos. Revista de Nutrição, Campinas, v. 24, n. 4, ago. 2011.

CAMPOS, A. M.; PACHANE, G. G. Vamos fazer da nossa vida uma obra de arte? Educ. Rev., Especial, Curitiba, 2010.

CAMPOS, P. B. B.; TENANI, L.; BERTI, L. As grafias não convencionais da coda silábica nasal: análise de dados de EJA. Alfa, rev. lingu., São José Rio Preto, v. 56, n. 2, dez. 2012.

CASTRO, S.; ALMEIDA, M. A. Ingresso e permanência de alunos com deficiência em universidades públicas brasileiras. Rev. bras. educ. espec., Marília, v. 20, n. 2, jun. 2014.

CATELLI JR, R.; GISI, B.; SERRAO, L. F. S. Encceja: cenário de disputas na EJA. R. Bras. Est. Pedag., Brasília, v. 94, n. 238, dez. 2013. 
CHRISPINO, A.; GONCALVES, D. E. Políticas públicas sistêmicas para a redução da violência: a visão de futuro e a resiliência. Ensaio: aval. pol. públ. educ., Rio de Janeiro, v. 21, n. 81, dez. 2013.

CIAVATTA, M.; RUMMERT, S. M. As implicaçóes políticas e pedagógicas do currículo na educação de jovens e adultos integrada à formação profissional. Educ. Soc., Campinas, v. 31, n. 111, jun. 2010.

CARVALHO, R. T. O discurso curricular intercultural na educação de jovens e adultos e a produção de subjetividades. Educ. Pesqui., São Paulo, v. 38, n. 1, abr. 2012

COSTA, L. S. O.; ECHEVERRIA, A. R. Contribuiçóes da teoria sócio-histórica para a pesquisa sobre a escolarização de jovens e adultos. Ciênc. Educ., Bauru, v. 19, n. 2, 2013.

DI PIERRO, M. C. A educação de jovens e adultos no Plano Nacional de Educação: avaliação, desafios e perspectivas. Educ. Soc., Campinas, v. 31, n. 112, set. 2010 .

DRAGANOV, P. B.; FRIEDLÄNDER, M. R.; SANNA, M. C. Andragogia na saúde: estudo bibliométrico. Esc. Anna Nery, Rio de Janeiro, v. 15, n. 1, mar. 2011.

FERREIRA, A. T. B. et al. Práticas dos professores alfabetizadores da EJA: o que fazem os professores, o que pensam os seus alunos? Educ. rev., Belo Horizonte, v. 29, n. 3, set. 2013.

FONSECA-JANES, C. R. X.; OMOTE, S. Os cursos de Pedagogia da Universidade Estadual Paulista e a Educação Inclusiva. Rev. bras. educ. espec., Marília, v. 19, n. 3, set. 2013.

FONSECA, M. C. F. R.; SIMOES, F. M. Apropriação de práticas de numeramento na EJA: valores e discursos em disputa. Educ. Pesqui., São Paulo, v. 40, n. 2, jun. 2014.

FRANCO, D. S. A gestão de Paulo Freire à frente da Secretaria Municipal de Educação de São Paulo (1989 - 1991) e suas consequências. Pro-Posiçóes, Campinas, v. 25, n. 3, dez. 2014.

FRIEDRICH, M. et al. Trajetória da escolarização de jovens e adultos no Brasil: de plataformas de governo a propostas pedagógicas esvaziadas. Ensaio: aval. pol. públ. educ., Rio de Janeiro, v. 18, n. 67, jun. 2010.

FRIEDRICH, M.; BENITE, C. R. M.; BENITE, A. M. C. Programa Nacional de Inclusão de Jovens: Projovem: uma análise entre a proposta oficial e a expe- 
riência vivida em Goiânia. Ensaio: aval. pol. públ. educ., Rio de Janeiro, v. 20, n. 74, p. 185-206, jan./mar. 2012.

GOMES, M. F. C. et al. Cultura, cognição e linguagem na constituição de práticas de leitura e escrita de adultos em processo de alfabetizaçáo. Psicol. Reflex. Crit., Porto Alegre, v. 24, n. 3, 2011.

GUIMARÃES, P. Educadores de adultos em Portugal: políticas fragmentadas, identidades em mudança. Ensaio: aval. pol. públ. educ., Rio de Janeiro, v. 18, n. 69, 2010.

IVO, A.; HYPOLITO, A. M. Educação profissional e PROEJA: processos de adesão e resistência à implantação de uma experiência. Educ. Rev., Belo Horizonte, v. 28, n. 3, set. 2012 .

JANUARIO, G.; FREITAS, A. V.; LIMA, K. Pesquisas e Documentos Curriculares no Âmbito da Educação Matemática de Jovens e Adultos. Bolema, Rio Claro, v. 28, n. 49, ago. 2014.

JULIÃO, E. F. O impacto da educação e do trabalho como programas de reinserção social na política de execução penal do Rio de Janeiro. Rev. bras. educ., Rio de Janeiro, v. 15, n. 45, set./dez. 2010.

LAFFIN, M. H. L. F.; NAKAYAMA, A. R. O trabalho de professores/as em um Espaço de privação de liberdade. Educ. Real., Porto Alegre, v. 38, n. 1, mar. 2013.

LEHNHARD, G. R.; MANTA; S. W; PALMA; L. E. A prática de atividade física na história de vida de pessoas com deficiência física. Rev. educ. fís./UEM, Maringá, v. 23, n. 1, mar. 2012.

LIMA, I. B.; SELVA, A. C. V. Jovens e adultos construindo e interpretando gráficos. Bolema, Rio Claro, v. 27, n. 45, abr. 2013.

MACEDO, S. R. H. et al. Adolescência e sexualidade: scripts sexuais a partir das representaçóes sociais. Rev. bras. enferm., Brasília, v. 66, n. 1, fev. 2013.

MADUREIRA, A. B. et al. Perfil de homens autores de violência contra mulheres detidos em flagrante: contribuiçóes para o enfrentamento. Esc. Anna Nery, Rio de Janeiro, v. 18, n. 4, dez. 2014.

MARQUES, D. T.; PACHANE, G. G. Formação de educadores: uma perspectiva de educação de idosos em programas de EJA. Educ. Pesqui., São Paulo, v. 36, n. 2, ago. 2010. 
MARTINS, M. V. R. Bibliotecas públicas e escolares nos discursos de Cecília Meireles e Armanda Álvaro Alberto: acervos e práticas de leituras. Perspect. ciênc. inf., Belo Horizonte, v. 19, dez., 2014.

MIRANDA, P. R.; GAZIRE, E. S. Saúde e números: uma parceria de sucesso. Bolema, Rio Claro, v. 26, n. 42B, abr. 2012.

. Interdisciplinaridade no PROEJA: uma proposta possível no caderno temático saúde e números. Bolema, Rio Claro, v. 27, n. 46, ago. 2013.

MORAES, C. S. V. Educação de jovens e adultos trabalhadores de qualidade: regime de colaboração e Sistema Nacional de Educação. Educ. Soc., Campinas, v. 34, n. 124, jul./set. 2013.

MORAES, C. S. V.; ALAVARSE, O. M. Ensino Médio: possibilidades de avaliação. Educ. Soc., Campinas, v. 32, n. 116, jul./set. 2011.

MOREIRA, A. F; FERREIRA, L. A. G. Abordagem temática e contextos de vida em uma prática educativa em ciências e biologia na EJA. Ciênc. educ., Bauru, v. 17, n. 3, 2011.

NOBRE, A.; ROAZZI, A. Realismo nominal no processo de alfabetização de crianças e adultos. Psicol. Reflex. Crit., Porto Alegre, v. 24, n. 2, 2011.

ONOFRE, E. M. C. JULIAO, E. F. A educação na prisão como política pública: entre desafios e tarefas. Educ. Real., v. 38, n. 1, p. 51-69, 2013.

ORDONEZ, T. N.; CACHIONI, M. Motivos para frequentar um programa de educação permanente: relato dos alunos da universidade aberta à terceira idade da Escola de Artes, Ciências e Humanidades da Universidade de São Paulo. Rev. bras. geriatr. gerontol., Rio de Janeiro, v. 14, n. 3, 2011.

PAVANELLO, R. M.; LOPES, S. E.; ARAUJO, N. S. R. Leitura e interpretação de enunciados de problemas escolares de matemática por alunos do ensino fundamental regular e educação de jovens e adultos (EJA). Educ. Rev., Curitiba, n. Especial, 2011.

PEDRALLI, R.; CERUTTI-RIZZATTI, M. E. Evasão escolar na educação de jovens e adultos: problematizando o fenômeno com enfoque na cultura escrita. Rev. bras. linguist. apl., Belo Horizonte, v. 13, n. 3, set. 2013.

PEDROSO, C. C. C.; ANDRADE, M. S. Representaçóes sociais sobre história por jovens e adultos. Psicol. Soc., Belo Horizonte, v. 26, n. 2, ago. 2014

PENARANDA-CORREA, F. et al. La praxis como fundamento de una educación para la salud alternativa: estudio de investigación-acción en el Programa 
de Crecimiento y Desarrollo en Medellín, Colombia. Interface, Botucatu, v. 15, n. 39, dez. 2011.

PERES, M. A. C. Velhice e analfabetismo, uma relação paradoxal: a exclusão educacional em contextos rurais da região Nordeste. Soc. Estado, Brasília, v. 26, n. 3, dez. 2011.

RESENDE, A. A. C. de; LACERDA, C. B. F. Mapeamento de alunos surdos matriculados na rede de ensino pública de um município de médio porte do Estado de São Paulo: dissonâncias. Rev. bras. educ. espec., Marília, v. 19, n. 03, set. 2013.

RIAÑO-GALAN, A. et al. La transición a la vida activa de las personas con discapacidad: expectativas familiares y grado de ajuste al trabajo. Rev. bras. educ. espec., Marília, v. 20, n. 2, jun. 2014.

RIBAS, M. G. Mulheres da Educação de Jovens e Adultos em busca da formação perdida: um olhar da educação musical. Educ. Rev., Curitiba, n. 53, jul. 2014.

RODRIGUES, G. T. et al. Psicologia e educaçáo de jovens e adultos: um desafio em construção. Psicol. Esc. e Educ., Maringá, v. 18, n. 1, jun. 2014.

RUMMERT, S. M.; ALVES, N. Jovens e adultos trabalhadores pouco escolarizados no Brasil e em Portugal: alvos da mesma lógica de conformidade. Rev. Bras. Educ., Rio de Janeiro, v. 15, n. 45, set./dez. 2010.

SCHNEIDER, S. M.; FONSECA, M. C. F. R.. Esse é o meu lugar... esse não é o meu lugar: inclusão e exclusão de jovens e de adultos na escola. Educ. Soc., Campinas, v. 34, n. 122, mar. 2013.

. Práticas Laborais nas Salas de Aula de Matemática da EJA: perspectivas e tensôes nas concepções de aprendizagem. Bolema, Rio Claro, v. 28, n. 50, dez. 2014.

SHIROMA, E. O; LIMA FILHO, D. L. Trabalho docente na Educação Profissional e Tecnológica e no PROEJA. Educ. Soc., Campinas, v. 32, n. 116, p. 725-743, jul./set. 2011.

SILVA, C. M. M. B.; SILVA NETO, J. G. A língua portuguesa no ensino médio: conteúdos de ensino e o desenvolvimento da aula. Alfa, rev. linguíst., São José Rio Preto, v. 57, n. 1, 2013.

SILVA, M. R. A política de integração curricular no âmbito do PROEJA: entre discursos, sujeitos e práticas. Ensaio: aval. pol. públ. educ., Rio de Janeiro, v. 19, n. 71, jun. 2011. 
SILVA, J. L.; BONAMINO, A. M. C.; RIBEIRO, V. M. Escolas eficazes na educaçáo de jovens e adultos: estudo de casos na rede municipal do Rio de Janeiro. Educ. Rev., Belo Horizonte, v. 28, n. 2, jun. 2012.

SILVA, L. H.; COSTA, V. A; ROSA, W. M. A educação de jovens e adultos em áreas de reforma agrária: desafios da formação de educadores do campo. Rev. Bras. Educ., Rio de Janeiro, v. 16, n. 46, jan./abr. 2011.

SILVA, M. S. et al. Risco de doenças crônicas transmissíveis na população atendida em Programa de Educação Nutricional em Goiânia (GO), Brasil. Ciênc. Saúde Coletiva, Rio de Janeiro, v. 19, n.5, p. 1409-1418, mai. 2014.

SOARES, L. As especificidades na formação do educador de jovens e adultos: um estudo sobre propostas de EJA. Educ. Rev., Belo Horizonte, v. 27, n. 2, ago. 2011.

SOUZA, C. M. Uma escola para homem rural: a cultura popular, os camponeses e o movimento de educação de base (1960-1964). Educ. Pesqui., São Paulo, v. 38, n. 2, jun. 2012.

SOUZA, M. C. R. F.; FONSECA, M. C. F. R. Práticas de numeramento e relaçóes de gênero: tensóes e desigualdades nas atividades laborais de alunas e alunos da EJA. Rev. Bras. Educ., Rio de Janeiro, v. 18, n. 55, dez. 2013 a.

- Territórios da casa, matemática e relaçóes de gênero na EJA. Cad. Pesqui., São Paulo, v. 43, n. 148, abr. 2013b.

STROMQUIST, N. P. Educação Latino-Americana em tempos globalizados. Sociologias, Porto Alegre, v. 14, n. 29, abr. 2012.

VARGAS, P. G.; GOMES, M. F. C. Aprendizagem e desenvolvimento de jovens e adultos: novas práticas sociais, novos sentidos. Educ. Pesqui., São Paulo, v. 39, n. 2, jun. 2013.

VOLPE, G. C. M. O financiamento da educação de jovens e adultos em municípios mineiros no período de 1996 a 2006: até quando migalhas? Rev. Bras. Educ., Rio de Janeiro, v. 18, n. 54, set. 2013.

VOVIO, C. L.; KLEIMAN, A. B. Letramento e alfabetização de pessoas jovens e adultas: um balanço da produção científica. Cad. Cedes, Campinas, v. 33, n. 90, ago. 2013.

ZIMMERMANN, N. et al. Fluência verbal livre, fonêmica e semântica: efeitos de idade e escolaridade, normas e discrepâncias. Psicol. Reflex. Crit., Porto Alegre, v. 27, n. 1, mar. 2014. 


\section{NOTAS}

1. O estudo partiu de pesquisa em andamento intitulada Transformação da EJA em Comunidade de Aprendizagem: atuaçóes educativas de êxito para um modelo social de EJA, coordenada pela Profa. Dra. Roseli Rodrigues de Mello, financiada pelo Conselho Nacional de Desenvolvimento Científico e Tecnológico (CNPq), que contempla a análise de conteúdo das publicaçóes sobre Educação de Jovens e Adultos e Comunidades de Aprendizagem, dos últimos cinco anos, em âmbito nacional e internacional.

2. Os artigos selecionados podem ser encontrados tanto via o endereço <http://www. scielo.org/php/index.php> quanto <http://www.scielo.br/> a partir dos descritores indicados. É importante ressaltar que a busca foi encerrada em 12 de fevereiro de 2015 e, desse modo, artigos publicados em 2014, mas, porventura, indexados após essa data, não puderam ser considerados.

3. Embora estes trabalhos estejam localizados no debate de educação ao longo da vida, optou-se por não os tratar no presente artigo, pois é perspectiva ainda em tensão no campo da EJA no país, a compreensão de espaço de formação universitária, inicial, continuada, em serviço etc., como pertencentes ao campo da Educação de Jovens e Adultos.

4. Cada artigo (A) recebeu um Código (Cód.): A1, A2, sucessivamente, tendo sido agrupados por categoria e por tema, ficando mais próximos na tabela os artigos que apresentam convergências em suas proposiçóes. Essa foi uma alternativa encontrada pelas autoras para substituir os nomes dos autores, considerando a grande quantidade da amostra aqui considerada.

Recebido em 20 de fevereiro de 2015.

Aprovado em 29 de maio de 2015.

DOI: http://dx.doi.org/10.1590/CC0101-32622015723757 